\title{
Use of anticholinergic drugs and worsening of pemphigus foliaceus in a patient with bipolar disorder
}

\author{
Uso de anticolinérgico e piora de pênfigo foliáceo em portador de transtorno \\ afetivo bipolar
}

\begin{abstract}
Dear Editor,
Pemphigus foliaceus (PF) refers to an autoimmune disease characterized by loss of epidermal intercellular adhesion manifesting as blistering and erosions of epithelial surfaces (acantholysis). ${ }^{1}$ It presents chronic course with little or no mucosal involvement. ${ }^{1}$ The onset of surface blisters in PF involves the action of autoantibodies lgG (mainly IgG4 subclass) directed agaist the cell adhesion molecules and appears to involve phosphorylation of intracellular proteins associated with desmosomes. The regulation of cell-to-cell and cell-matrix keratocytes is mediated by an important function of the keratinocyte (KC) acetylcholine (ACh) axis. ${ }^{2}$

Acetylcholine and cholinergic drugs can alter the assembly/disassembly of intercellular junctions of KCs and modify the shape and motility of KC in an autocrine/paracrine pattern. Either nicotinic or muscarinic antagonists cause acantholysis in $\mathrm{KC}$ monolayers ${ }^{2}$. The cholinergic agonists can reverse acantholysis induced by antagonists. ${ }^{3}$ Clinical trials using pyridostigmine bromide suggest that nonsteroidal treatment of PF patients can be achieved by pharmacologically stimulating keratinocyte cell-to-cell adhesion through the keratinocyte $\mathrm{ACh}$ axis. ${ }^{4}$

Psychotropic drugs with antimuscarinic activity seem to precipitate and/or worsen pemphigus. However, few case reports are available in literature about drugs with anticholinergic properties inducing adverse effects.
\end{abstract}

\section{Case report}

A 48-year-old female patient, with a 10-year-history of bipolar disorder type I, using valproic acid 1,500 mg, with appropriate serum level, and comorbity with Pemphigus foliaceous. During outpatient follow-up, she had frequent manic relapses, particularly when using high steroids doses (deflazarcot) for treatment of pemphigus recrudescence. The last manic relapse was associated with corticosteroids dose increase. Risperidone $2 \mathrm{mg}$ has been started, titrated to a dose of $4 \mathrm{mg} /$ day, reaching euthymia. She developed severe parkinsonism after risperidone was started, and biperiden has been associated with improvement of Parkinson syndrome. After the association with anticholinergic drug, there was worsening of bullous lesions and reduced effectiveness of the combination of glucocorticoids with immunosuppressive drugs (azathioprine) in the treatment of pemphigus. Thus, biperiden and risperidone were discontinued and the patient was started on Seroquel XRO $600 \mathrm{mg} /$ day, she remained euthymia and had significant improvement of bullous lesions.

Pemphigus destroys the patient's appearance and is a difficult-to-treat illness requiring long-term hospitalization and immunosuppressive treatment. ${ }^{1}$ Thus, it is expected that a disease as compromising represents a significant psychological impairment to the patient. Therefore, patients with bipolar disorder, for which stressful events represent a significant impact on the destabilization of humor, ${ }^{5}$ may be further compromised by serious comorbidities such as pemphigus, further worsening the prognosis. Thus, in the treatment of bipolar comorbidity with active pemphigus, to maintain an effective and well tolerated regimen, the use of anticholinergic drugs may be not recommended.

Lúcio Botelho-Nogueira ${ }^{1}$, Lucas Quarantini², Ângela Miranda-Scippa

${ }^{1}$ Universidade Federal da Bahia, Hospital Universitário Professor Edgard Santos, Psiquiatria

${ }^{2}$ Universidade Federal da Bahia (UFBA), Hospital Universitário Professor Edgard Santos, Brazil 


\section{Disclosures}

Lúcio Botelho-Nogueira

Employment: Universidade Federal da Bahia (UFBA), Hospital Universitário Professor Edgard Santos, Brazil.

Lucas Quarantini

Employment: Universidade Federal da Bahia (UFBA), Hospital Universitário Professor Edgard Santos, Brazil.

Ângela Miranda-Scippa

Employment: Universidade Federal da Bahia (UFBA), Hospital Universitário Professor Edgard Santos, Brazil.

* Modest

** Significant

*** Significant: Amounts given to the author's institution or to a colleague for research in which the author has participation, not directly to the author.

\section{References}

1. Namaz MR. Prescribing antidepressant drugs for pemphigus patients: An important point to keep in mind. Dermatol Online J. 2004;10(1):22.

2. Grando SA. Cholinergic control of epidermal cohesion. Exp Dermatol. 2006;15(4):265-82.

3. Grando SA, Dahl MV. Activation of keratinocyte muscarinic acetylcholine receptors reverses pemphigus acantholysis. J Eur Acad Dermatol Venereol. 1993:2:72-86.

4. Grando SA. New approaches to the treatment of pemphigus. J Investig Dermatol Symp Proc. 2004;9(1):84-91.

5. Quarantini LC, Miranda-Scippa A, Nery-Fernandes F, AndradeNascimento M, Galvão-de-Almeida A, Guimarães JL, Teles CA, Netto LR, Lira SB, de Oliveira IR,Post RM, Kapczinski F, Koenen $\mathrm{KC}$. The impact of comorbid posttraumatic stress disorder on bipolar disorder patients. J Affect Disord. 2010;123(1-3):71-6. 